\title{
The Importance of Conscious Diet and Physical Exercise in the 21st Century: Qualitative Analytical Review Research
}

\author{
Abdi, Ellie ${ }^{1 *}$, Taiar, Redha ${ }^{2}$, Shalbaf, Ashkan ${ }^{3}$ \\ ${ }^{I}$ Montclair State University, USA \\ ${ }^{2}$ University of Reims, France \\ ${ }^{3}$ The American University of Paris, France
}

*Corresponding Author: Abdi, Ellie, Montclair State University, USA

\begin{abstract}
This analytical review research used facts already available and analyzed the information in an attempt to explain complex phenomenon effects of unhealthy eating and lack of exercise among young adults ages between 18 to 30. Total of 230 peer reviewed articles, government and organization reports were reviewed which 82 based on relativity were chosen. Effects of unhealthy diets and lack of exercising as well reasons on such behaviors of young adults ages between 18 to 30 were examined. The conclusion drawn from this analytical review attested that a single cause cannot explain and a single policy cannot reverse the two epidemics. Rather many factors such as education can be used as a strategy.
\end{abstract}

\section{INTRODUCTION}

The evaluations were made in regards to the effects of unhealthy diet and lack of physical activity among young adults ages between 18 to 30 years old. As an analytical review does not describe or identify what rather attempts to establish why and how this papers was written in response to three assigned questions, 1) How does unhealthy diet effect the young adults ages between 18 to 30 years old? 2) How does lack of exercise effect the young adults ages between 18 to 30 years old? 3) Why are there unhealthy diet habits and physical inactivity rates among young adults aged between 18 to 30 ? From this analytical research, details on food industry and overall effects of poor diet and unhealthy lifestyle among young adults were discussed.

\section{BACKGROUND}

To satisfy hunger in an instinctively way is to eat in order to feel content. Eating consciously is to trigger pleasant sensory responses and place body to a safe emotional state. In contrast once there is a desperate edge to hunger, food is swallowed and not chewed appropriately which produces an uncomfortable full feeling. This is eating unconsciously. According to World Health Organization (WHO) (nd.) physical activity is defined as any bodily movement produced by skeletal muscles that requires energy expenditure. According to the same source physical inactivity is identified as the fourth leading risk factor for global mortality ( $6 \%$ of deaths globally). In addition inactivity is estimated to be the main cause for approximately $21 \%$ to $25 \%$ of breast and colon cancers, $27 \%$ of diabetes, and approximately $30 \%$ of heart disease burden.

\subsection{Problem Statement}

The increasing prevalence of poor health in connection to lack of health diet and exercising is receiving significant public, political and economic attention (Sonntag, Schneider, Mdege, Ali, \& Schmidt, 2015). With respect to this recognition, for years, research has found that changes in physical activity and caloric intake provide effective treatment of healthy lifestyle(Baillot, Romain, Boisvert-Vigneault, Audet, Baillargeon, Dionne, \&Langlois, 2015;Burgess, Hassmén, Welvaert, \&Pumpa, 2017; Dalle Grave, Calugi, Centis, El Ghoch, \&Marchesini, 2010; Rogers, Carter, Williams, \&Courneya, 2018; Wadden, Butryn, \& Byrne, 2004).By investigating the older pieces of research (Croll, Neumark-Sztainer, \& Story, 2001; Hayes \& Ross, 1987;Mourao, Bressan, Campbell, \& Mattes, 2007; Pietiläinen, Kaprio, Borg, Plasqui, Yki-Järvinen, Kujala, \&Rissanen, 2008) to more recent ones 
(Al-Nakeeb, Lyons, Dodd, \& Al-Nuaim, 2015; Shiri, Solovieva, Husgafvel-Pursiainen, Telama, Yang, Viikari, \&Viikari-Juntura, 2013; Zhu, Hsu, \& Hollis, 2013) it became comprehensible, that the problem is such that young adults do not carry a healthy diet and suffer from lack of exercising. Therefore this study attempted to understand the effects of unhealthy diet and physical inactivity with respect to food industry, poor diet and unhealthy lifestyle among the purposed population in economically developed countries.

Renee (2017) explained that unhealthy diets resulted in a poor nutrient-to-calorie ratio, which can lead to weight gain and malnutrition as well as related health problems. Accompanying with WHO characterizing physical inactivity as the fourth leading risk factor for mortality worldwide, over years this rate increased from physical inactivity from 1.9 million in 2005 to 3.2 million in 2008 and 5.3 million in 2012 (da Silva, de Oliveira, Bertin, de Oliveira, Pires, Spadaccini, \& de Almeida PiresOliveira, 2018).

\subsection{Purpose Statement}

Using the present research within the past 5 years, the purpose of this qualitative analytical review study was divided into 3 sections: 1) to inform individuals on current research to explore the effects of unhealthy diet and physical inactivity with consideration given to food industry and overall poor diet and unhealthy lifestyle among the purposed population, 2) to familiarize individuals on current trends of proposed issues and, 3) hope that individuals benefit from this study. The research older than 5 years were used as historical reference.

\subsection{Research Questions}

This qualitative analytical review was framed by three research questions that were explored through already available information. The following questions reflected the direction of the study. Implications from the research questions can be best practices for understanding the issue.

- How does unhealthy diet effect the generation between ages 18 to 30 years old?

- How does lack of exercise effect the generation between ages 18 to 30 years old?

- Why are there unhealthy eating habits and physical inactivity rates among young adults aged between 18 to 30 ?

\section{METHODS}

Published documents on effects of unhealthy eating habits and lack of exercise with respect to food industry, overall poor diet and unhealthy lifestyle among the purposed population were processed in 5 steps. Results were carefully accessed and conclusion was drawn.

The protocol was organized by: 1) the authors met the task accurately by scholarly advanced search on google scholars, government files, Education Research Information Center (ERIC), ProQuest, Live strong, World Health Organization [WHO], US Center for Disease Control [CDC], 2) relevant studies were judged in terms of their usefulness in answering the research questions with $75 \%$ of references within the last 5 years. Two hundred ninety three (293) abstracts were reviewed and among those 230 papers and government articles plus 10 figures were considered. The 79 most related studies and 3 figures were chosen to be included in this paper. These articles met the quality criteria. Due to broad spectrum of the study, a meta-analysis was not possible. Therefore, a narrative synthesis of the included studies was conducted to summarize the key features of research questions, methods and results,3) The results of the separate studies were brought together to give an overall measure of qualitative effectiveness for combination outcome, and 4) the focus was on methodical analysis of published literature, concentrating on content rather than the number of studies analyzed.

\subsection{Unhealthy Diet Effects on Young Adults Ages between 18 to 30 Years Old}

Economic development in most areas of the world has resulted in increased purchasing power and available food per capita. Supermarkets and a growing fast-food industry have transformed the dietary pattern (Zobel, Hansen, Rossing, \& von Scholten, 2016). Compared to 50 years ago, the world's largest food companies have a bigger voice in shaping the world's dietary choices by producing more of the calories that the world consumes, and reaching inside the minds of more consumers 
(Freudenberg, 2018). Nevertheless, ultra-processed products are claiming an ever larger portion of global caloric consumption (Moreira, Baraldi, Moubarac, Monteiro, Newton, Capewell, \& O'Flaherty, 2015; Steele, Popkin, Swinburn, Monteiro, 2017).

Identified by Roberto, Swinburn, Hawkes, Huang, Costa, Ashe, and Brownell (2015) food systems, food environments, and the food industry are the leading cause of obesity. Yet, according to Lifshitz and Lifshitz (2014) the root cause of the obesity epidemic not merely is the food industry but also the governmental policies as well. Schrempf, (2014) examined how fast-food chains are socially connected to obesity which in terms if true, government policies and social connectivity make obesity difficult to escape in the US and now worldwide.

\section{Unhealthy diets and its effects}

\section{$\%$ of adults unaware about the link between unhealthy diets and health problems}

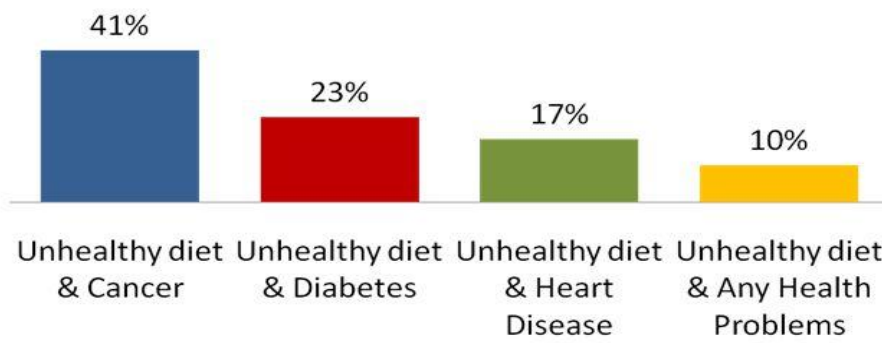

Figure1: Heart Foundation and Cancer Research (2010)

World cancer research fund. Retrieved from https://www.google.com/search? $q=$ effects + of + unhealthy+diet

To validate Figure 1. WHO (2018) confirmed that an unhealthy diet is one of the major risk factors for a range of chronic diseases, including 1) cardiovascular diseases, 2) cancer, 3) diabetes and other conditions linked to obesity. Only eight years prior in 2010 WHO (2011) identified four main risk factors for non-communicable diseases: 1) unhealthy diets, 2) tobacco use, 3) alcohol use and 4) sedentary behavior. A mounting body of evidence also showed that the practices of the food, alcohol and tobacco industries play a significant role in the growing non-communicable diseases burden (Allen \& Feigl, 2017; Collin, Hill, Eltanani, Plotnikova, Ralston, \& Smith, 2017; McKee \&Stuckler, 2018).

Furthermore poor nutrition can impair the daily health, wellbeing, and reduce the ability to lead an enjoyable and active life. In the short term, poor nutrition can contribute to 1) stress, 2) tiredness,and3) capacity to work, and over time, it can 1) contribute to the risk of developing some illnesses and 2) other health problems such as: a) being overweight or obese, b) tooth decay, c) high blood pressure, d) high cholesterol, e) heart disease and stroke, f) type-2 diabetes, g) osteoporosis, h) some cancers, depression, i) eating disorders (Government of South Australia, 2018).

Obesity epidemic, has been described by Michelle Obama among others as a national security (Christenson, Taggart, Messner-Zidell, Kiernan, Cusick, \& Day, 2012; Popkin, 2011). Therefore, developing military-sponsored weight management programs for new US soldiers are considered (Hruby, Hill, Bulathsinhala, McKinnon, Montain, Young, \& Smith, 2015). Excess body weight among service members and recruits is associated with 1) lower physical performance, 2) medical ineligibility for service, 3) earlier separation, and 4) billions in attributable Department of Defense costs (Gubata, Niebuhr, Cowan, 2012). Increased sedentary military work, significant sitting periods 
during commuting, lack of leisure time, and unhealthy dietary habits have caused a considerable increase in the number of physically unfit soldiers (Leyk, Witzki, Willi, Rohde, \&Rüther, 2015) thus understanding health and physical fitness are key factors for soldiers.

\subsection{Interventions}

Freeland-Graves and Nitzke (2013) called for 1) behavioral theory and 2) evidence-based strategies to increase the effectiveness of nutrition education. Callahan (2013) suggested the lifestyle interventions to reduce the risk of overweight through interdisciplinary curriculum areas such as 1) personal, 2) social, and 3) health education as essential ways to reduce rate of obesity. Access to health care, education, healthy food and recreational activities that permit weight maintenance are important in trends of healthy lifestyle (Malik, Willett, \& Hu, 2013).

Many of the nutritional problems of Americans-not just obesity - can be traced to the food industry to encourage people to eat more in order to generate sales and increase income (Nestle, 2013). Nevertheless US recent reports have proposed promising policies to modify harmful food industry practices (Gittelsohn, Trude, \& Kim, 2017; Hawkes, Smith, Jewell, Wardle, Hammond, Friel, \&Kain, 2015). Some of these practical polices of the food industry are:

- Restrict marketing of breast milk substitutes (Munn, Newman, Mueller, Phillips, \& Taylor, 2016).

- Reduce salt intake in food (Jaenke, Barzi, McMahon, Webster, \& Brimblecombe, 2017).

- Replace trans-fat with polyunsaturated fat (Downs, Bloem, Zheng, Catterall, Thomas, Veerman, $\& \mathrm{Wu}, 2017)$.

- Tax sugar or sugary beverages (Roache \& Gostin, 2017).

- Mandate warning labels on unhealthy products such as soda (Lee, Ferguson, Hertenstein, Adam, Zenkov, Wang, \& Brown, 2018).

- Require front-of-pack labels (Nestle, 2018).

Besides the United States, some countries are trying to prevent obesity through healthier diets and government assistance such as Singapore which works with food industry to encourage production of healthier food products through Healthier Choice Symbol (Hawkes, Jewell, \& Allen, 2013).

\subsection{Lack of Exercise Effects on Young Adults Ages between 18 to 30 Years Old}

Adults should exercise at least 150 minutes of moderate-intensity (equal to a brisk walk) or 75 minutes of vigorous-intensity activity (faster heartbeat and breathing, and sweat) each week, preferably spread throughout the week (American Cancer Society 2014).Despite increasing knowledge concerning the relationship between physical activity and health, the society have become an increasingly sedentary. Coincidently, WHO had defined the lack of exercise and a sedentary lifestyle as major risk factors for various diseases ( $\mathrm{Gu}$, Coomans, Hu, Scheer, Stanley, \& Meijer, 2015).However there is still a direct link between the behavioral risk factors such as lack of exercise which leads to obesity in addition to poor diet and smoking (van den Berk-Clark, Secrest, Walls, Hallberg, Lustman, Schneider, \&Scherrer, 2018).

Lack of physical activity has clearly shown to be a risk factor for many conditions. Coexisting with this statement John Hopkins Medicine (2018) relates physical inactivity to cardiovascular diseases such as developing coronary heart disease even after researchers accounted for 1) smoking, 2) alcohol use, and 3) diet. In addition the same source listed other conditions such as 1) high blood pressure, 2) type 2 diabetes, 3) anxiety and 3) depression, 4) increase the risk of certain cancers and 5) overweight or obesity to inactive lifestyle. The American Cancer Society (2014) with the recommendation of the Center for Disease Control and Prevention (CDC) released a very close list to the John Hopkins Medicine's study. The society confirmed that engaging in physical activity can lower the risk for 1) cancer, 2) heart disease, and 3) stroke (Pedersen, 2017). To support this study, Hirschey and Lipkus (2017) delineated that breast cancer survivors attributed lack of exercise as causes for cancer diagnosis and recurrence risk. 


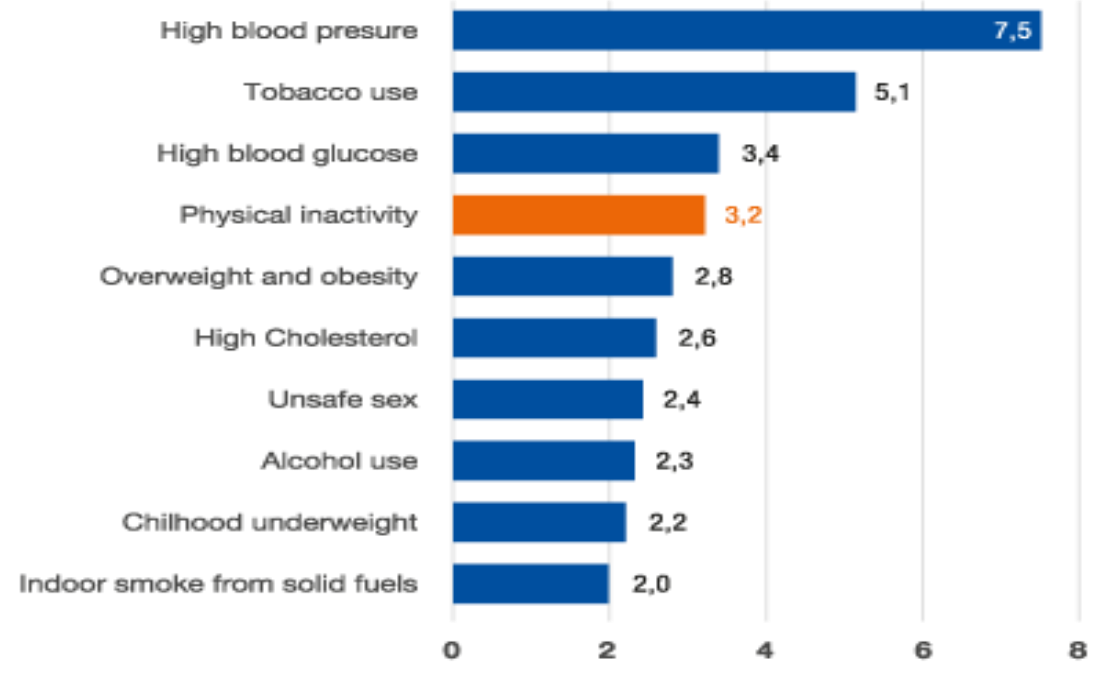

Figure2: WHO 2010. Top ten leading risk factors for global mortality (millions of deaths), 2004

The impact of insufficiently-active lifestyles can be seen through comparing inactivity's role in global mortality with those of other risk factors. As illustrated in the chart, physical inactivity has been identified as the fourth leading risk factor for global mortality. A 2009 study by WHO estimated that physical inactivity accounted for roughly 6\% of global deaths in 2004 equal to around 3.2 million deaths in that year. (International Sport and Culture Association [ISCA] 2015).

As Thomas Jefferson argued, "a strong body makes the mind strong" strategies that delay the onset and progression of dementia can be linked to physical activity which is cost-effective for the promotion of brain health. The effects of exercising on brain is well documented (Kennedy, Hardman, Macpherson, Scholey, \&Pipingas, 2017; Ruegsegger, \& Booth, 2017; Voss, Weng, Burzynska, Wong, Cooke, Clark, \&McAuley, 2016) that as a human is aging it becomes imperative to remain physically active. In addition, the economic burden of physical inactivity cost of health-care systems internationally was estimated at $\$ 53.8$ billion worldwide in 2013 (Ding, Lawson, Kolbe-Alexander, Finkelstein, Katzmarzyk, Van Mechelen, \& Lancet. Physical Activity Series 2 Executive Committee, 2016).

Freudenberg (et al., 2018) suggested 1) individual behavior, 2) local, national and global public policies, 3) demographic shifts and 4) changes in the global economy as contributors to the problem. In a systematic review by Mayne, Auchincloss, and Michael, (2015) evaluated 1) the efficacy of policy and 2) built environment changes on obesity outcomes of BMI, diet or physical activity. Among other public health interventions in obesity research education and information (Palou \&Bonet, 2013) demonstrated its highly standing.

\subsection{Reasons for Unhealthy Diet Habits and Physical Inactivity Rates among Adults Ages 18 to 30 Years Old}

In 1998 Glanz, Basil, Maibach, Goldberg, and Snyder (1998) suggested that nutritional concerns were less relevance to most people than taste and cost. Then provided by Higgs (2015) explored that social norms about eating has a powerful effect on both food choice and intake. Specifically expressed norms are a powerful influence on behavior and norm following is greater shared identity. A diverse sample of 1,201 students at a 2-year community college and a 4-year public university in the Twin Cities, MN, completed the Student Health and Wellness Study survey in spring 2010. About half (49\%) of young adults placed moderate to high importance on alternative production practices, and few demographic differences across attitudes were found (Pelletier, Laska, Neumark-Sztainer, \& Story, 2013). Therefore positive attitudes toward organic, local, and sustainable foods are associated with higher dietary quality among young adults which is promising in norm trend.

In the last 30 years, obesity rates have doubled in adults, tripled in children, and quadrupled in adolescents ([CDC] 2014/2014; Ogden Carrol 2015).Nevertheless, from 1990 to 2010, the United States made substantial progress in improving health: 1) life expectancy at birth and healthy life 
expectancy increased, 2) all-cause death rates at all ages decreased, 3) and age-specific rates of years lived with disability remained stable.

United States also made an increase in the popularity of sufficient physical activity from 2001 to 2009 which had a small impact on obesity prevalence (Dwyer-Lindgren, Freedman, Engell, Fleming, Lim,Murray, \&Mokdad, 2013).Despite substantial progress in improving health, an unhealthy diet in the US was the leading risk factor for more than 500,000 deaths in 2016 dominating deaths from 1) heart disease, 2) stroke, 3) diabetes, 4) cancer. After unhealthy diet, 1) tobacco, 2) high blood pressure, and 3) obesity were the next biggest early death risks (Mokdad, Ballestros, Echko, Glenn, Olsen, Mullany, \&Kasaeian, 2018).

Knowing that the United States spends the most per capita on health care across all countries ([OECD] health data, 2012; [WHO], 2013) the US lacks universal health coverage, and lags behind other high-income countries for life expectancy (Wang, Dwyer-Lindgren, Lofgren, Rajaratnam, Marcus, Levin-Rector, \& Murray, 2012). In addition, chronic disability accounted for nearly half of the US health burden, and improvements in population health in the United States have not kept pace with advances in population health in other wealthy nations. (Murray, Abraham, Ali, Alvarado, Atkinson, Baddour, \&Bolliger, 2013).
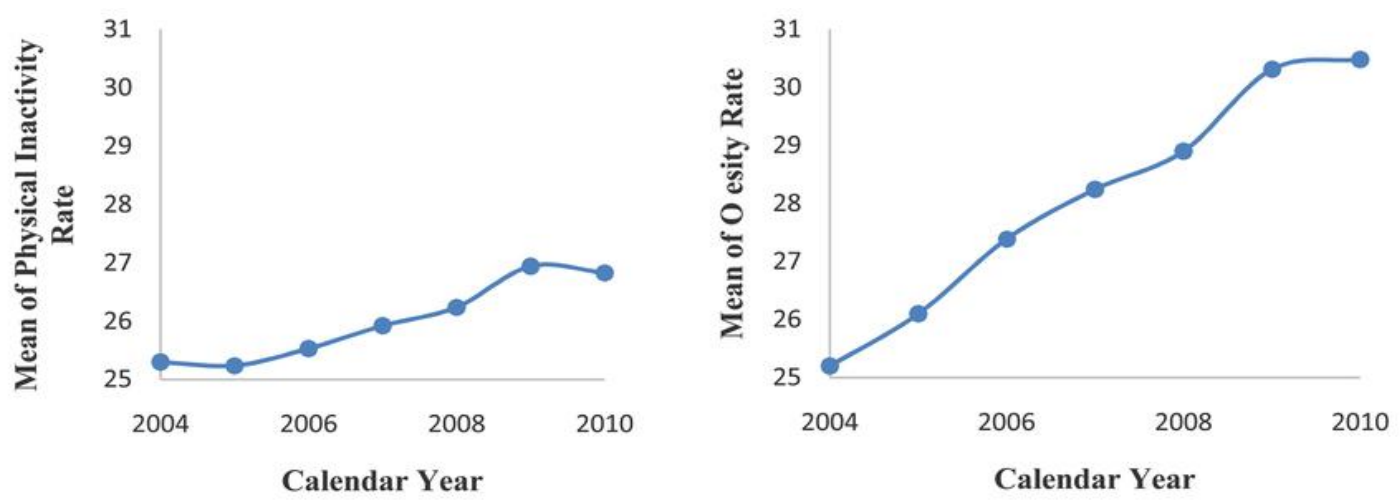

Figure3: The annual trend in physical inactivity and obesity rates from 2004 to 2010

Centers for Disease Control and Prevention [CDC]. (2014). Childhood Obesity Facts.

Utilizing Center for Disease Control and Prevention [CDC] 2004-2010 with figure (3) the study conducted longitudinal analyses to examine neighborhood built environment and obesity risk controlling for the effects of socio-demographic characteristics. Results of the study showed that higher street connectivity and walk score are related to lower physical inactivity and obesity rates, while the ratio of fast-food restaurants and number of extreme weather events are positively related to physical inactivity and obesity (Xu, Liu, Chen, Shao, \& Fu, 2017).

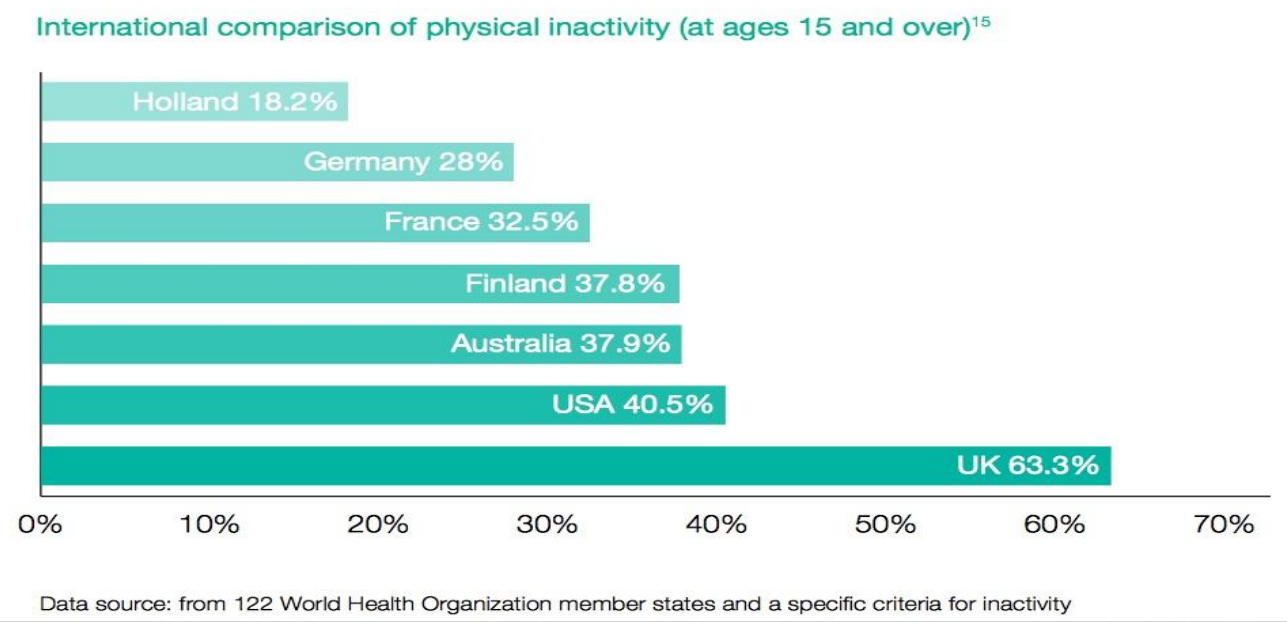

Figure4: Published at Cycling Embassy of Great Britain. 2018

Retrieved from https://www.cycling-embassy.org.uk/blog/2018/01/08/health-physical-inactivity-obesity-andcycling 
Worldwide, the biggest killers are now diseases that are attributable to 1) behavioral, 2) dietary, 3) environmental, and 4) metabolic risk factors linked directly to human behavior (Di Cesare, Khang, Asaria, Blakely, Cowan, Farzadfar, \&Oum, 2013). According to WHO (nd) every year, around 3.2 million people on earth die prematurely as a result of physical inactivity. Collected data from 17,928 undergraduate university students worldwide confirmed that four in each ten students are physically inactive (Pengpid, Peltzer, Kassean, Tsala, Sychareun, \& Müller-Riemenschneider, 2015).

\section{Results}

WHO (nd.) recommended at least 150 minutes of moderate aerobic activity a week, or 75 minutes of vigorous aerobic activity, for adults as regular physical activity reduces the risk of 1) developing cardiovascular disease, 2) type 2 diabetes, 3) dementia, and 4) some cancers by at least 30\%. Nonetheless, physical activity alone does not promote weight loss (Malhotra, Noakes, \&Phinney, 2015) but it has significant impact on health. Poor nutrition can endorse excessweight substantially which contributes to 1) endometrial, 2) kidney, and 3) liver cancer, low physical activity contribute to 1) endometrial, 2) Kidney, and 3) lung cancer and dietary factors such as lack of fruits and vegetables and high meat and salt intake mainly contribute to 1) colorectal, 2) breast, and 3) lung cancer. (Behrens, Gredner, Stock, Leitzmann, Brenner, \& Mons, 2018). Established in this analytical review, both lack of proper nutrition and physical activity promote noncommunicable diseases therefore prevention, control, policy, health service and education interventions are required.

\section{CONCLUSION AND RECOMMENDATION}

In analyzing of many documents it became apparent that each research suggested one or few strategies of combating the epidemics of unhealthy diet and lack of exercise. Some of these studies were driven from common themes and some were different. The review confirmed that policies and changes to build altered environments are promising targets for desired preventions. No single objective can be explained the rapid growth of non-communicable diseases nevertheless two themes of education and policies are driven from this current study. In health education areas of healthy personal and social lifestyles, wellness and healthcare stress need to be explored. In the area of policies practical government policies need to be implemented. To identify new opportunities for preventing non-communicable diseases, researchers need to investigate on how the food industry practices that contribute to diet-related non-communicable diseases were changed. No single policy also can be extracted to reverse the epidemics therefore it is suggested that the expanded efforts are necessary in education.

\section{REFERENCES}

[1] Allen, L. N., \& Feigl, A. B. (2017). Reframing non-communicable diseases as socially transmitted conditions. The Lancet Global Health, 5(7), e644-e646.

[2] Al-Nakeeb, Y., Lyons, M., Dodd, L. J., \& Al-Nuaim, A. (2015). An investigation into the lifestyle, health habits and risk factors of young adults. International journal of environmental research and public health, 12(4), 4380-4394.

[3] American Cancer Society. (2014). CDC: lifestyle changes can reduce death from top 5 causes. Retrieved from https://www.cancer.org/latest-news/cdc-lifestyle-changes-can-reduce-death-from-top-5-causes.html

[4] Baillot, A., Romain, A. J., Boisvert-Vigneault, K., Audet, M., Baillargeon, J. P., Dionne, I. J.,\&Langlois, M. F. (2015). Effects of lifestyle interventions that include a physical activity component in class II and III obese individuals: a systematic review and meta-analysis. PLoS One, 10(4), e0119017.

[5] Barha, C. K., Galea, L. A., Nagamatsu, L. S., Erickson, K. I., \& Liu-Ambrose, T. (2017). Personalising exercise recommendations for brain health: considerations and future directions. Br J Sports Med, 51(8), 636-639.

[6] Behrens, G., Gredner, T., Stock, C., Leitzmann, M. F., Brenner, H., \& Mons, U. (2018). Cancers Due to Excess Weight, Low Physical Activity, and Unhealthy Diet: Estimation of the Attributable Cancer Burden in Germany. DeutschesÄrzteblatt International, 115(35-36), 578

[7] Burgess, E., Hassmén, P., Welvaert, M., \&Pumpa, K. L. (2017). Behavioural treatment strategies improve adherence to lifestyle intervention programmes in adults with obesity: a systematic review and meta-analysis. Clinical obesity, 7(2), 105-114.

[8] Callahan, D. (2013). Obesity: Chasing an elusive epidemic. Hastings Center Report, 43(1), 34-40.

[9] Centers for Disease Control and Prevention [CDC]. (2014). Childhood Obesity Facts. 
[10] Centers for Disease Control and Prevention [CDC]. (2014). NCHS Health E-Stat: Prevalence of Overweight, Obesity, and Extreme Obesity among Adults, United States, 1960-1962 through 2011-2012.

[11] Christenson, W., Taggart, A., Messner-Zidell, S., Kiernan, M., Cusick, J., Day, R. (2012). Still too fat to fight. Retrieved from http://missionreadiness.s3.amazonaws.com/wp-content/uploads/Still-Too-Fat-ToFight-Report.pdf.

[12] Collin, J., Hill, S. E., Eltanani, M. K., Plotnikova, E., Ralston, R., \& Smith, K. E. (2017). Can public health reconcile profits and pandemics? An analysis of attitudes to commercial sector engagement in health policy and research. PloS one, 12(9), e0182612

[13] Croll, J. K., Neumark-Sztainer, D., \& Story, M. (2001). Healthy eating: what does it mean to adolescents?.Journal of nutrition education, 33(4), 193-198.

[14] Dalle Grave, R., Calugi, S., Centis, E., El Ghoch, M., \&Marchesini, G. (2010). Cognitive-behavioral strategies to increase the adherence to exercise in the management of obesity. Journal of obesity, 2011.

[15] da Silva, J. L., de Oliveira, R. F., Bertin, L. D., de Oliveira, P. D., Pires, F. B., Spadaccini, A. F., \& de Almeida Pires-Oliveira, D. A. (2018). Physical inactivity and associated factors in adults of a basic health unit: An observational cross-sectional study. Manual Therapy, Post urology\& Rehabilitation Journal, 16, 0-0.

[16] Di Cesare, M., Khang, Y. H., Asaria, P., Blakely, T., Cowan, M. J., Farzadfar, F., \&Oum, S. (2013). Inequalities in non-communicable diseases and effective responses. The Lancet, 381(9866), 585-597.

[17] Ding, D., Lawson, K. D., Kolbe-Alexander, T. L., Finkelstein, E. A., Katzmarzyk, P. T., Van Mechelen, W., \& Lancet Physical Activity Series 2 Executive Committee (2016). The economic burden of physical inactivity: a global analysis of major non-communicable diseases. The Lancet, 388(10051), 1311-1324.

[18] Downs, S. M., Bloem, M. Z., Zheng, M., Catterall, E., Thomas, B., Veerman, L., \& Wu, J. H. (2017). The impact of policies to reduce trans fat consumption: A systematic review of the evidence. Current Developments in Nutrition, 1(12), cdn-117.

[19] Dwyer-Lindgren, L., Freedman, G., Engell, R. E., Fleming, T. D., Lim, S. S., Murray, C. J., \&Mokdad, A. H. (2013). Prevalence of physical activity and obesity in US counties, 2001-2011: a road map for action. Population health metrics, 11(1), 7.

[20] Freeland-Graves, J. H., \&Nitzke, S. (2013). Position of the academy of nutrition and dietetics: total diet approach to healthy eating. Journal of the Academy of Nutrition and Dietetics, 113(2), 307-317.

[21] Freudenberg, N., (2018). Changing Food Industry Practices that contribute to diet-related chronic diseases. CUNY, Urban food policy Institute. Retrieved from http://www.cunyurbanfoodpolicy.org/news/2018/9/ 17/changing-food-industry-practices-that-contribute-to-diet-related-chronic-diseases

[22] Gittelsohn, J., Trude, A. C. B., \& Kim, H. (2017). Peer Reviewed: Pricing Strategies to Encourage Availability, Purchase, and Consumption of Healthy Foods and Beverages: A Systematic Review. Preventing chronic disease, 14.

[23] Glanz, K., Basil, M., Maibach, E., Goldberg, J., \& Snyder, D. A. N. (1998). Why Americans eat what they do: taste, nutrition, cost, convenience, and weight control concerns as influences on food consumption. Journal of the American Dietetic Association, 98(10), 1118-1126.

[24] Government of South Australia (2018). The risk of poor nutrition. Department of Health and Wellbeing. Retrieved from https://www.sahealth.sa.gov.au/wps/wcm/connect/public

[25] Gu, C., Coomans, C. P., Hu, K., Scheer, F. A., Stanley, H. E., \& Meijer, J. H. (2015). Lack of exercise leads to significant and reversible loss of scale invariance in both aged and young mice. Proceedings of the National Academy of Sciences, 201424706.

[26] Gubata, M., Niebuhr, D., Cowan, D. (2012). Accession Medical Standards Analysis, Research Activity: 2012 Annual Report. Bethesda, MD: Division of Preventive Medicine, Walter Reed Army Institute of Research.

[27] Hawkes, C., Jewell, J., \& Allen, K. (2013). A food policy package for healthy diets and the prevention of obesity and diet-related non-communicable diseases: the NOURISHING framework. Obesity reviews, 14, 159-168.

[28] Hawkes, C., Smith, T. G., Jewell, J., Wardle, J., Hammond, R. A., Friel, S., \&Kain, J. (2015). Smart food policies for obesity prevention. The Lancet, 385(9985), 2410-2421.

[29] Hayes, D., \& Ross, C. E. (1987). Concern with appearance, health beliefs, and eating habits. Journal of Health and Social Behavior, 120-130.

[30] Higgs, S. (2015). Social norms and their influence on eating behaviours. Appetite, 86, 38-44.

[31] Hirschey, R., \&Lipkus, I. (2017, March). Breast cancer survivors' attributions of lack of exercise as causes for cancer diagnosis and recurrence risk. In Annals of Behavioral Medicine (vol. 51, pp. s1790-s1791). 233 Spring St, New York, NY 10013 USA: springer. 
[32] Hruby, A., Hill, O. T., Bulathsinhala, L., McKinnon, C. J., Montain, S. J., Young, A. J., \& Smith, T. J. (2015). Trends in overweight and obesity in soldiers entering the US Army, 1989-2012. Obesity, 23(3), 662-670.

[33] International Sport and Culture Association [ISCA] (2015). The economic cost of physical inactivity in Europe. Retrieved from https://inactivity-time- bomb.nowwemove.com/download-report/The\%20Economic\%20 Costs\%20of\%20Physical\%20Inactivity\%20in\%20Europe\%

[34] Jaenke, R., Barzi, F., McMahon, E., Webster, J., \& Brimblecombe, J. (2017). Consumer acceptance of reformulated food products: A systematic review and meta-analysis of salt-reduced foods. Critical reviews in food science and nutrition, 57(16), 3357-3372.

[35] John Hopkins Medicine. (2018). What health risks are linked to physical inactivity? Retrieved from https:// www.hopkinsmedicine.org/healthlibrary/conditions/cardiovascular_diseases/risks_of_physical_inactivity

[36] Kennedy, G., Hardman, R. J., Macpherson, H., Scholey, A. B., \&Pipingas, A. (2017). How does exercise reduce the rate of age-associated cognitive decline? A review of potential mechanisms. Journal of Alzheimer's Disease, 55(1), 1-18.

[37] Lee, B. Y., Ferguson, M. C., Hertenstein, D. L., Adam, A., Zenkov, E., Wang, P. I., \& Brown, S. T. (2018). Simulating the impact of sugar-sweetened beverage warning labels in three cities. American journal of preventive medicine, 54(2), 197-204.

[38] Leyk, D., Witzki, A., Willi, G., Rohde, U., \&Rüther, T. (2015). Even one is too much: sole presence of one of the risk factors overweight, lack of exercise, and smoking reduces physical fitness of young soldiers. The Journal of Strength \& Conditioning Research, 29, S199-S203.

[39] Lifshitz, F., \&Lifshitz, J. Z. (2014). Globesity: the root causes of the obesity epidemic in the USA and now worldwide. Pediatric endocrinology reviews: PER, 12(1), 17-34.

[40] OECD health data 2012 - frequently requested data. Retrieved from http://www.oecd.org/health/healthsystems/oecdhealthdata2012-frequentlyrequesteddata.htm.

[41] Palou, A., \&Bonet, M. L. (2013). Challenges in obesity research. Nutricionhospitalaria, 28(5).

[42] Pedersen, B. K. (2017). Anti-inflammatory effects of exercise: role in diabetes and cardiovascular disease. European journal of clinical investigation, 47(8), 600-611.

[43] Pelletier, J. E., Laska, M. N., Neumark-Sztainer, D., \& Story, M. (2013). Positive attitudes toward organic, local, and sustainable foods are associated with higher dietary quality among young adults. Journal of the Academy of Nutrition and Dietetics, 113(1), 127-132.

[44] Pengpid, S., Peltzer, K., Kassean, H. K., Tsala, J. P. T., Sychareun, V., \& Müller-Riemenschneider, F. (2015). Physical inactivity and associated factors among university students in 23 low-, middle-and highincome countries. International journal of public health, 60(5), 539-549.

[45] Pietiläinen, K. H., Kaprio, J., Borg, P., Plasqui, G., Yki-Järvinen, H., Kujala, U. M., \&Rissanen, A. (2008). Physical inactivity and obesity: a vicious circle. Obesity, 16(2), 409-414.

[46] Popkin, B. M. (2011). Is the obesity epidemic a national security issue around the globe?.Current opinion in endocrinology, diabetes, and obesity, 18(5), 328.

[47] Malhotra, A., Noakes, T., \&Phinney, S. (2015). It is time to bust the myth of physical inactivity and obesity: you cannot outrun a bad diet.

[48] Malik, V. S., Willett, W. C., \& Hu, F. B. (2013). Global obesity: trends, risk factors and policy implications. Nature Reviews Endocrinology, 9(1), 13.

[49] Mayne, S. L., Auchincloss, A. H., \& Michael, Y. L. (2015). Impact of policy and built environment changes on obesity-related outcomes: a systematic review of naturally occurring experiments. Obesity reviews, 16(5), 362-375.

[50] McKee, M., \& Stuckler, D. (2018). Revisiting the corporate and commercial determinants of health. American journal of public health, 108(9), 1167-1170.

[51] Mokdad, A. H., Ballestros, K., Echko, M., Glenn, S., Olsen, H. E., Mullany, E., \&Kasaeian, A. (2018). The state of US health, 1990-2016: burden of diseases, injuries, and risk factors among US states. Jama, 319(14), 1444-1472.

[52] Moreira, P. V., Baraldi, L. G., Moubarac, J. C., Monteiro, C. A., Newton, A., Capewell, S., \&O’Flaherty, M. (2015). Comparing different policy scenarios to reduce the consumption of ultra-processed foods in UK: impact on cardiovascular disease mortality using a modelling approach. PLoS One, 10(2), e0118353.

[53] Mourao, D. M., Bressan, J., Campbell, W. W., \& Mattes, R. D. (2007). Effects of food form on appetite and energy intake in lean and obese young adults. International journal of obesity, 31(11), 1688.

[54] Munn, A. C., Newman, S. D., Mueller, M., Phillips, S. M., \& Taylor, S. N. (2016). The impact in the United States of the baby-friendly hospital initiative on early infant health and breastfeeding outcomes. Breastfeeding Medicine, 11(5), 222-230. 
[55] Murray, C. J., Abraham, J., Ali, M. K., Alvarado, M., Atkinson, C., Baddour, L. M., \&Bolliger, I. (2013). The state of US health, 1990-2010: burden of diseases, injuries, and risk factors. Jama, 310(6), 591-606.

[56] Nestle, M. (2013). Food politics: How the food industry influences nutrition and health (Vol. 3). Univ of California Press.

[57] Nestle, M. (2018). Public health implications of front-of-package labels. American journal of public health, 108(3), 320-320.

[58] Ogden C, Carrol M. (2015).Prevalence of Obesity among Children and Adolescents: United States, Trends 1963-1965 through 2007-2008, 2010.

[59] Renee, J. (2017). What are the effects of an unhealthy diet? Retrieved from https://www.livestrong.com/ article/200742-what-are-the-effects-of-an-unhealthy-diet

[60] Roache, S. A., \&Gostin, L. O. (2017). The untapped power of soda taxes: incentivizing consumers, generating revenue, and altering corporate behavior. International journal of health policy and management, 6(9), 489.

[61] Roberto, C. A., Swinburn, B., Hawkes, C., Huang, T. T., Costa, S. A., Ashe, M., \& Brownell, K. D. (2015). Patchy progress on obesity prevention: emerging examples, entrenched barriers, and new thinking. The Lancet, 385(9985), 2400-2409.

[62] Rogers, L. Q., Carter, S. J., Williams, G., \&Courneya, K. S. (2018). Physical activity. In Handbook of Cancer Survivorship (pp. 287-307). Springer, Cham.

[63] Ruegsegger, G. N., \& Booth, F. W. (2017). Running from disease: molecular mechanisms associating dopamine and leptin signaling in the brain with physical inactivity, obesity, and type 2 diabetes. Frontiers in endocrinology, 8, 109.

[64] Schrempf, J. (2014). A social connection approach to corporate responsibility: The case of the fast-food industry and obesity. Business \& Society, 53(2), 300-332.

[65] Shiri, R., Solovieva, S., Husgafvel-Pursiainen, K., Telama, R., Yang, X., Viikari, J., \&Viikari-Juntura, E. (2013, June). The role of obesity and physical activity in non-specific and radiating low back pain: the Young Finns study. In Seminars in arthritis and rheumatism (Vol. 42, No. 6, pp. 640-650). WB Saunders.

[66] Sonntag, D., Schneider, S., Mdege, N., Ali, S., \& Schmidt, B. (2015). Beyond food promotion: a systematic review on the influence of the food industry on obesity-related dietary behavior among children. Nutrients, 7(10), 8565-8576.

[67] Steele, E. M., Popkin, B. M., Swinburn, B., \& Monteiro, C. A. (2017). The share of ultra-processed foods and the overall nutritional quality of diets in the US: evidence from a nationally representative crosssectional study. Population health metrics, 15(1), 6.

[68] van den Berk-Clark, C., Secrest, S., Walls, J., Hallberg, E., Lustman, P. J., Schneider, F. D., \&Scherrer, J. F. (2018). Association between posttraumatic stress disorder and lack of exercise, poor diet, obesity, and co-occuring smoking: A systematic review and meta-analysis. Health Psychology, 37(5), 407.

[69] Voss, M. W., Weng, T. B., Burzynska, A. Z., Wong, C. N., Cooke, G. E., Clark, R., \&McAuley, E. (2016). Fitness, but not physical activity, is related to functional integrity of brain networks associated with aging. Neuroimage, 131, 113-125.

[70] Wadden, T. A., Butryn, M. L., \& Byrne, K. J. (2004). Efficacy of lifestyle modification for long-term weight control. Obesity research, $12(\mathrm{~S} 12), 151 \mathrm{~S}-162 \mathrm{~S}$

[71] Wang, H., Dwyer-Lindgren, L., Lofgren, K. T., Rajaratnam, J. K., Marcus, J. R., Levin-Rector, A., \& Murray, C. J. (2012). Age-specific and sex-specific mortality in 187 countries, 1970-2010: a systematic analysis for the Global Burden of Disease Study 2010. The Lancet, 380(9859), 2071-2094.

[72] World Health Organization (nd.), Global Strategy on Diet, Physical Activity and Health Retrieved 11/17/18 fromhttps://www.who.int/dietphysicalactivity/pa/en/

[73] World Health Organization (nd). Physical activity and Adults. Retrieved from https://www.who.int/diet physicalactivity/factsheet_adults/en/)

[74] World Health Organization. (2011). Global status report on noncommunicable diseases 2010. Geneva: World Health Organization.

[75] World Health Organization (2013). Global health expenditure database. Retrieved from http://www.who. int/nha/expenditure_database/en/.

[76] World Health Organization (2018). Noncommunicable diet. Retrieved from http://www.emro.who.int/ noncommunicable-diseases/causes/unhealthy-diets.html 
[77] Xu, Y., Liu, Y.H., Chen, T., Shao, W.Y. and Fu, Z.L. (2017). A Longitudinal Analysis of Environment and Risk of Obesity in the US. Journal of Geoscience and Environment Protection, 5, 204-220

[78] Zhu, Y., Hsu, W. H., \& Hollis, J. H. (2013). The impact of food viscosity on eating rate, subjective appetite, glycemic response and gastric emptying rate. PLoS One, 8(6), e67482.

[79] Zobel, E. H., Hansen, T. W., Rossing, P., \& von Scholten, B. J. (2016). Global changes in food supply and the obesity epidemic. Current obesity reports, 5(4), 449-455.)

Citation: Abdi, Ellie, Taiar, Redha, Shalbaf, Ashkan. "The Importance of Conscious Diet and Physical Exercise in the 21st Century: Qualitative Analytical Review Research "International Journal of Sports and Physical Education (IJSPE), vol 5, no. 4, 2019, pp. 12-22. doi: http://dx.doi. org/10.20431/2454-6380.0504003.

Copyright: (C) 2019 Authors. This is an open-access article distributed under the terms of the Creative Commons Attribution License, which permits unrestricted use, distribution, and reproduction in any medium, provided the original author and source are credited. 